\title{
Underwater drones reveal different fish community structures on the steep slopes of a tropical reservoir
}

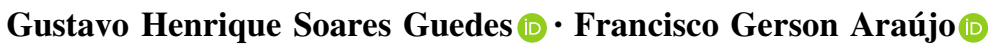

Received: 27 June 2021/Revised: 13 December 2021/ Accepted: 17 December 2021 / Published online: 30 January 2022

(C) The Author(s), under exclusive licence to Springer Nature Switzerland AG 2022

\begin{abstract}
A new approach for visual fish survey in reservoirs using underwater drones (remotely operated vehicle- ROV) is presented. The ROV was applied to identify abiotic gradients and to compare fish assemblages on the steep slopes in a tropical reservoir. The tested hypothesis is that fish are concentrated in the littoral zone due to the better physicochemical and habitat conditions, compared to deep and hypoxic layers. Twelve species were recorded (seven native, five exotic), with all species occurring in the littoral zone, seven species in the transition, and four in the profundal zone. A greater fish abundance and richness was found in the littoral zone corroborating the main hypothesis. The littoral zone was dominated by exotic cichlids (Cichla spp., Coptodon rendalli), while native catfish (Loricariichthys castaneus, Pimelodella lateristriga) occupied deeper areas. The fish distribution seems to be driven by local factors, such as oxygen availability and habitat structure. The preference for the littoral zone by alien cichlids may have led to the
\end{abstract}

Handling Editor: Fernando M. Pelicice

Supplementary Information The online version contains supplementary material available at https://doi.org/10.1007/ s10750-021-04790-9.

G. H. S. Guedes · F. G. Araújo ( $\square)$

Laboratório de Ecologia de Peixes, Universidade Federal

Rural Do Rio de Janeiro, Km 7, BR-465, 23890-000,

Seropédica, Rio de Janeiro, Brazil

e-mail: gersonufrrj@gmail.com extirpation/decrease of native characids and induced catfishes to occupy deep habitats. Underwater drones can be a valuable tool for the simultaneous collection of abiotic/biotic data, especially in deep reservoirs with complex habitats, resulting in advances in the environmental monitoring.

Keywords Remotely operated vehicle - Vertical stratification · Underwater video $\cdot$ Littoral-profundal zones $\cdot$ Environmental gradients

\section{Introduction}

Reservoirs are non-natural ecosystems with important multiple uses, but also drivers of severe environmental changes in inland waters. The environmental impact of each dam is unique (Agostinho et al., 1999, 2008; Dias et al., 2021), however, one of the common effects is the elevation of the water level, which can vary from a few centimeters (e.g. run-of-the-river hydroelectric plants with low water storage) to more than $100 \mathrm{~m}$ in large accumulation dams. In deep tropical reservoirs, the heating of surface layers can result in seasonal thermal stratification, with well-defined water layers, with different water densities and physicochemical characteristics during the summer (Winton et al., 2019). The rise in water level and stratification causes abrupt environmental changes, especially in the 
reservoir deeper layers, giving rise to static, anoxic and homogeneous habitats (Wetzel, 2001; Straškraba \& Tundisi, 2013).

In this new scenario, fish tend to occupy reservoir littoral zones, a converging pattern that includes different fish taxa in different regions of the world (Gido et al., 2009; Říha et al., 2015; Agostinho et al., 2016; Baumgartner et al., 2018). The shoreline has greater habitat structure (e.g. branches and aquatic macrophytes) and the water physicochemical conditions are more suitable for the fish development compared to deep zones (Gois et al., 2012; Strayer \& Findlay, 2010). As a result, these areas are exploited by fish for breeding, feeding and shelter (Agostinho et al., 2007; Oliveira \& Goulart, 2008). In contrast, few species have pre-adaptations capable of circumventing anaerobic conditions and low food availability in the deeper layers (Fernando \& Holčík, 1991). These spatial patterns are temporally dynamic, including circadian and seasonal changes in vertical fish distribution mediated by biotic (e.g., ontogeny, predator avoidance) and abiotic (e.g., water column stratification) factors (Mehner, 2012; Muška et al., 2013).

Different methods have been used to determine the vertical distribution of fish in reservoirs, such as gillnets positioned in different layers of the water column (Prchalová et al., 2008), telemetry (Goulon et al., 2018), environmental DNA ( Blabolil et al., 2021) and hydroacoustic (Busch \& Mehner, 2009; Pollom \& Rose, 2016). These methods allow important advances in aquatic ecology, but like any tool, they possess certain biases and limitations. Hydroacoustic methods, for example, sometimes can lead to misinterpretation of fish for bubbles, in addition to presenting limitations related to the so-called acoustic dead zones, which affect the ability to identify specimens in complex and deep habitats (Lucas \& Barras, 2000; Busch \& Mehner, 2009; Tušer et al., 2014). Although hydroacoustic cameras as DIDSON are able to recognize species, the beam of echosounder is very narrow (Tušer et al., 2014), and also have limitations related to acoustic dead zones (Lucas \& Barras, 2000; Busch \& Mehner, 2009; Tušer et al., 2014). On the other hand, gillnets are invasive and known to be a selective technique for certain species, morphotypes and/or biotypes (Oliveira et al., 2014). For this reason, the combination of different methods has been used to reduce the specific biases of each methodology and to provide a more accurate description of fish assemblages (Kubečka et al., 2009). To date, the ability of small Remotely Operated Vehicles (ROVs) as a tool for simultaneously collecting both abiotic and biotic information, has not been properly tested in reservoirs.

The ROVs are submersible robotic systems controlled from the surface in real time. Each ROV has technical specificities according to the manufacturer and the purpose of use, with great variation in power, autonomy, depth, accessories, and price (Sward et al., 2019). However, this equipment is basically composed of a camera mounted in an impermeable enclosure, with propellers for maneuver, attached to a cable on the surface through which a video and telemetry signals are transmitted (Murrie et al., 2014). Small ROVs ( -3 to $20 \mathrm{~kg}$ ) are popularly known as underwater drones. Currently, a series of real-time sampling devices are available to be attached to certain models, such as benthic fauna suction samplers, robotic arms, multiparameter probes, sonars, optical systems to quantify zooplankton and hydrophones (Lima et al., 2020; McLean et al., 2020; Monk et al., 2020), making ROVs a powerful multi-tool for aquatic environmental monitoring. The application of ROVs as a nondestructive method for the visual survey of fish is a rapidly growing field, but most researches have been focused to marine environments (Sward et al., 2019), still with rare applications in inland waters (Alin et al., 1999; Guedes et al., 2020). In this context, video transects using underwater drones equipped with multiparameter probes can be valuable for simultaneously collecting physicochemical, habitat and fish distribution information, especially in the deepest and less studied reservoir layers.

The main objective of this study is to present a new approach for obtaining environmental data and fish occurrences in freshwater reservoirs by visual survey using underwater drones (small ROV class). The ROV was used in the steep slopes of a tropical reservoir (oligo-mesotrophic and warm monomictic) located in Southeast Brazil during the summer to identify the abiotic gradient (habitat + physicochemical) from the littoral to the profundal zone, and to compare fish assemblages (abundance and richness) in that gradient. The tested hypothesis is that fish are concentrated in the littoral zone because of the better physicochemical and habitat conditions, when compared with deep and hypoxic layers of the reservoir. In addition, we present for the first time the advantages, biases, and 
limitations of underwater drones' application in reservoirs. Finally, we hope to contribute to a better understanding of the processes that modulate the distribution of fish in altered environments and the development of this new non-invasive technique for environmental monitoring in inland waters.

\section{Methods}

Study area

The Lajes Reservoir $\left(22^{\circ} 42^{\prime}-22^{\circ} 50^{\prime} \mathrm{S}\right.$; $\left.43^{\circ} 53-44^{\circ} 32^{\prime} \mathrm{W}\right)$, State of Rio de Janeiro, Brazil, was constructed between 1905 and 1907, and is one of the oldest water impoundments designed for the primary purpose of generating electricity in Brazil (Brazilian Committee on Dams, 2011). The reservoir area is dendritic, with several embayment areas and islands (Online Resource 1). The margins are steep and the maximum depth is $45 \mathrm{~m}$ close to the dam. The average water inflow is $13.7 \mathrm{~m}^{3} \times \mathrm{s}^{-1}$, of which most $\left(8.3 \mathrm{~m}^{3} \times \mathrm{s}^{-1}\right)$ come from an inter-basin diversion (Guedes et al., 2020). The water retention time ( -300 days) and water transparency (euphotic zone $=9.2 \mathrm{~m}$ ) are high, with predominance of oligomesotrophic conditions (Soares et al., 2008; Klippel et al., 2020). Lentic conditions predominate in the longitudinal extent of the reservoir associated with the high retention time (Araújo et al., 2021). The water column presents thermal stratification typical of warm monomictic water bodies, with a stratified warm period, and mixing (complete or partial) during the cold period (Branco et al., 2009). The climate is seasonal tropical with dry winters (Aw), according to the Köppen-Geiger classification.

Vertical zones along steep slopes

Three zones were compared along the vertical/environmental gradient (habitat + physicochemical) following the steep slopes of the reservoir: littoral, transition and profundal (Fig. 1). The littoral zone comprises depths between 0 and $7 \mathrm{~m}$, the transition zone between 7 and $15 \mathrm{~m}$, and the profundal zone > $15 \mathrm{~m}$. The definition of the limits and dimensions of the vertical zones were based on different zonation

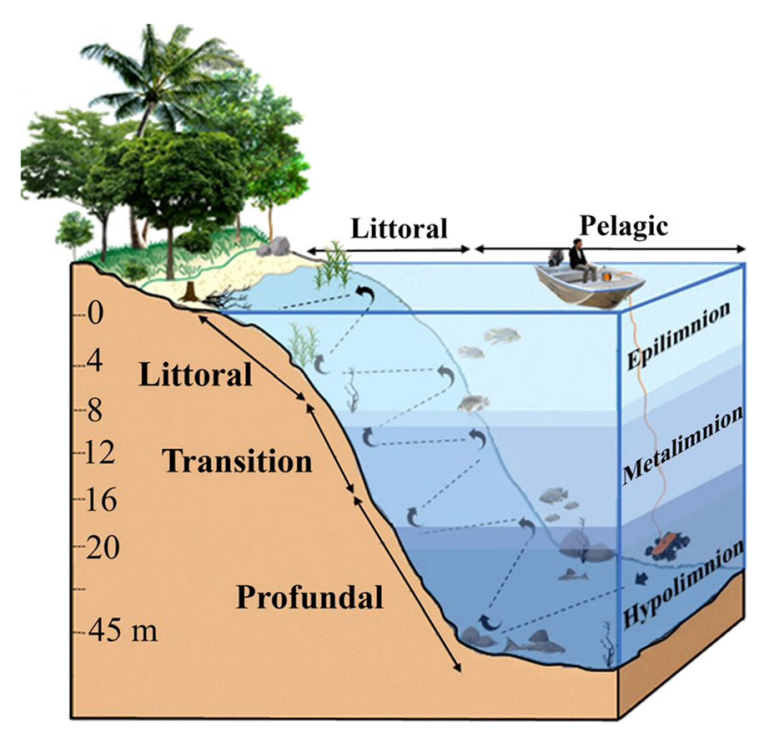

Fig. 1 Schematic model showing the dimensions and limits (in meters) of the zones along the steep slopes (littoral, transition and profundal), physicochemical water stratification column (eplimnion, metalimnion and hypolimnion) of the Lajes Reservoir during the summer

concepts (e.g. Wetzel, 2001; Lewis, 2009). In addition, we follow Matthews (1998) and Oliveira \& Goulart (2008) who emphasized the need to expand the purely limnological compartmentalization in lentic environments, for a zoning that also includes the effects of habitat components on the potential distribution of fish. In general, the vertical zonal boundaries vary in space and time according to the geographical location and functional characteristics of each reservoir. Therefore, we conducted standardized sampling only in lentic areas of the reservoir during the period of thermochemical stratification (October-2019 and April-2020; with the exception of March-2020 due to the rise of the COVID-19 Pandemic in Brazil) in two periods of the day (day: 09:00-16:00; and night: 19:00-01:00).

\section{Transect design}

A ROV model Genneino T1 (Shenzen, China) was used to sample fish and abiotic data in the vertical gradient. The ROV is small $(39 \times 34 \times 6 \mathrm{~cm}$, width $\times$ length $\times$ height $)$ and lightweight $(4.4 \mathrm{~kg})$, and is equipped with a camera attached $(1 / 2.5$ inches SONY CMOS, $4 \mathrm{k}$ resolution, FOV $160^{\circ}$ ), automatic 
stabilization systems, artificial lights (3000 lumens), sensors of depth (in meters) and temperature $\left({ }^{\circ} \mathrm{C}\right)$ capable of operating at $150 \mathrm{~m}$ of depth. The transects followed the margin slope, beginning in the profundal zone with ascending route in zigzag to the littoral zone (Fig. 1). The ROV was operated at a constant speed of $-0.25 \mathrm{~m} / \mathrm{s}$, an altitude of $1.5 \mathrm{~m}$ above the ground, angled filming fixed at $30^{\circ}$ towards the bed, with lights always on. The fixed depth and direction were automatically maintained by self-adjusting the speed of the thrusters, based on the real-time processing of the pressure sensor and dipping compass. The operation was carried out from a boat by two people, one in charge of the filming and the other controlling the cables (Fig. 2). The steps of pre-sampling, field procedures and post-sampling procedures were carried out following recommendations proposed by Monk et al. (2020).

The width of the transects was delimited by the field of view of the camera lens (FOV $160^{\circ}$ ), which corresponded to an observable horizontal distance of approximately $2 \mathrm{~m}$. Each vertical zone was sampled for $-7 \mathrm{~min}$. The total length of the transects was defined as $-105 \mathrm{~m}$, based on the equation $d=v \times t$, where $\mathrm{d}$ is the displacement, $\mathrm{v}$ is the speed $(-0.25 \mathrm{~m} /$ $\mathrm{s})$, and $\mathrm{t}$ is time $(7 \mathrm{~min}=420 \mathrm{~s})\left[d=0.25 \mathrm{~m} \times \mathrm{s}^{-1}\right.$ $\times 420 \mathrm{~s}=105 \mathrm{~m}]$. The approximate total area of each transect was $\sim 210 \mathrm{~m}^{2}(2.0 \mathrm{~m}$ wide $\times 105 \mathrm{~m}$ long $)$. Because of certain reservoir localities were too shallow, the transition zone was not sampled in 8 occasions, and the profundal zone in 20 occasions. The sampling unit was defined as the total number of fish observed in each transect, totaling 260 samples ([8 transects $\times 3$ zones $\times 2$ periods (day / night) $\times 6$

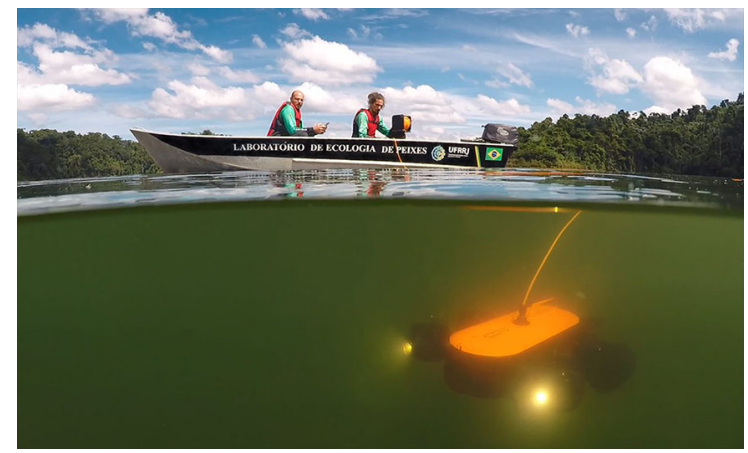

Fig. 2 Remotely operated vehicle model Genneino T1 being operated from a boat in the Lajes Reservoir, Rio de Janeiro State, Brazil months] - 28 samples not taken due to depth limitations). In 12 occasions, no fish were recorded, and these samples were included in the analysis by inserting a dummy variable (Clarke et al., 2006).

\section{Data extraction from video}

For each specimen observed within the transected range, biotic (species and estimated abundance) and abiotic (temperature $-{ }^{\circ} \mathrm{C}$ and depth $-\mathrm{m}$ ) information were recorded in real time (still in the boat). Dissolved oxygen $\left(\mathrm{mg} \times \mathrm{L}^{-1}\right)$ was measured at every 1-m depth with a YSI PROOD probe (Ohio, USA) before performing the ROV transects. The habitat coverage rate (rocky or clay substrate, branches, leaves) observed close to the fish were arbitrarily quantified through a protocol of grades (0-3): $0=$ no coverage; 1 = low coverage; $2=$ moderate coverage; $3=$ high coverage. In the laboratory, the videos were reanalyzed on a computer, with the results of the first annotation being checked and supplemented. A single viewer watched all video records to avoid multiple observers bias. Fish were identified to the species level following Santos et al. (2014); only the Cichla spp. (Cichla kelberi Kullander \& Ferreira, 2006 and Cichla piquiti Kullander \& Ferreira, 2006) that have similar morphology and color were identified to the genus level.

\section{Data analysis}

To understand the patterns of environmental variables (habitat + physicochemical) in relation to the vertical gradient and periods, samples were analyzed through a combined approach of univariate and multivariate techniques. First, a two-way ANOVA on aligned ranks transformation (ANOVA ART; function art in the ARTool package; Kay \& Wobbrock, 2020) was used to compare each environmental variable between the vertical zones (littoral, transition and profundal) and the diel cycle (day and night). When significant differences were detected, an a posteriori Tukey HSD was conducted at the 0.01 confidence level. Only environmental variables that differed significantly between zones/diel periods were used in the subsequent multivariate analysis. A Permutational Analysis of Variance (PERMANOVA; function adonis in the Vegan package; Oksanen et al., 2019) was used to compare the multivariate environmental data between 
the vertical zones and diel cycle (fixed factors). PERMANOVA was applied using 9999 permutations and square sum (partial) to calculate the p-values. When significant differences were detected $(p<0.01)$, paired comparisons were conducted between the groups. We used nonparametric tests because data were non-normal, even after using various data transformations. A principal component analysis (PCA) was applied on the standardized environmental data to identify spatial patterns. Because environmental data have different units of measurements, they were transformed to standard z-scores, i.e., they become dimensionless before submitting to multivariate analysis.

Spatial and temporal comparisons of the fish assemblage structure, total number of individuals (N) and total number of species (S) were also performed with PERMANOVA. Fish abundance data were previously log-10 transformed to reduce the influence of abundant species but preserve information on their relative abundance (Borcard et al., 2011). Then, the data were transformed into a Bray-Curtis "zero adjusted" similarity matrix, to circumvent the uncertainty of the Bray-Curtis coefficient ratio due to the presence of samples (12 transects) without fish records (Clarke et al., 2006). To determine the fish species that most contributed to within-group similarity, a multilevel pattern analysis (MPA, multipatt function, from the indicspecies package) was used. This analysis determines the association between zones and periods for each species separately. Significant values were detected based on the IndVal index that was tested through a permutation test (Cáceres \& Legendre, 2009). Because the slightly unbalanced design, the richness patterns in relation to zones were analyzed through a combined analysis of rarefaction and extrapolation techniques based on Hill numbers ( $q=0)$ using $i N E X T$ package (Hsieh et al., 2016). All analyses were conducted in $\mathrm{R}$ environment ( $\mathrm{R}$ Core Team, 2020).

\section{Results}

Vertical environmental gradient

Strong and expected differences in the environmental variables (physicochemical + habitat) were detected between the vertical zones by PERMANOVA $(P=128.8, \quad P<0.001)$, whereas periods (day $\times$ night) and interactions zone $\times$ period had no significant differences (Table 1; Online Resource 2). Vertical zoning explained $49 \%$ of the variation in the set of environmental variables, and the post-hoc tests showed paired differences between all zone comparisons $(P<0.001)$. The environmental changes between the different vertical zones were depicted in the first PCA axis $(57.6 \%$ of the explained variation, Fig. 3; Online Resource 3). The littoral zone was positively associated with higher temperatures and oxygen concentrations, and a substrate with higher branches and leaves coverage. Conversely, the profundal zone exhibited low temperatures and oxygen concentrations as the depth increases. The transition
Table 1 Results of twoway ANOVA on aligned ranks transformation (Anova ART) and the permutational analysis of variance (PERMANOVA) comparing the environmental variables between the vertical zones and periods

\begin{tabular}{lllll}
\hline Anova ART & Zone & Period & Zone $\times$ Period & Post-hoc test \\
\hline Temperature $\left({ }^{\circ} \mathrm{C}\right)$ & $275.2^{* * *}$ & 3.12 & 4.2 & Lit $>$ Tra $>$ Pro \\
Dissolved oxygen $(\mathrm{mg} / \mathrm{L})$ & $488.1^{* * *}$ & 3.63 & $10.7 * * *$ & Lit $>$ Tra $>$ Pro \\
Depth (m) & $981.1 * * *$ & $7.2^{* *}$ & 0.4 & Lit $<$ Tra $<$ Pro \\
Leaves $(\%)$ & $48.1 * * *$ & 0.7 & 1.11 & Lit $=$ Tra $>$ Pro \\
Branchs (\%) & $80.2^{* * *}$ & 4.6 & $7.4 * *$ & Lit $>$ Tra $>$ Pro \\
Clay $(\%)$ & 0.5 & 1.5 & 1.1 & Lit $=$ Tra $>$ Pro \\
Rocks $(\%)$ & $17.5 * * *$ & 0.9 & 2.2 & Lit $=$ Tra $>$ Pro \\
PERMANOVA & Df & Pseudo-F & $\mathrm{R} 2$ & Lit $\neq$ Tra $\neq$ Pro \\
Zone & 2 & $128.8 * * *$ & 0.49 & \\
Period & 1 & 1.6 & $>0.01$ & \\
Zone $\times$ Period & 2 & 2.19 & $>0.01$ & \\
Residuals & 254 & & 0.49 & \\
Total & 259 & & 1 & \\
\hline
\end{tabular}




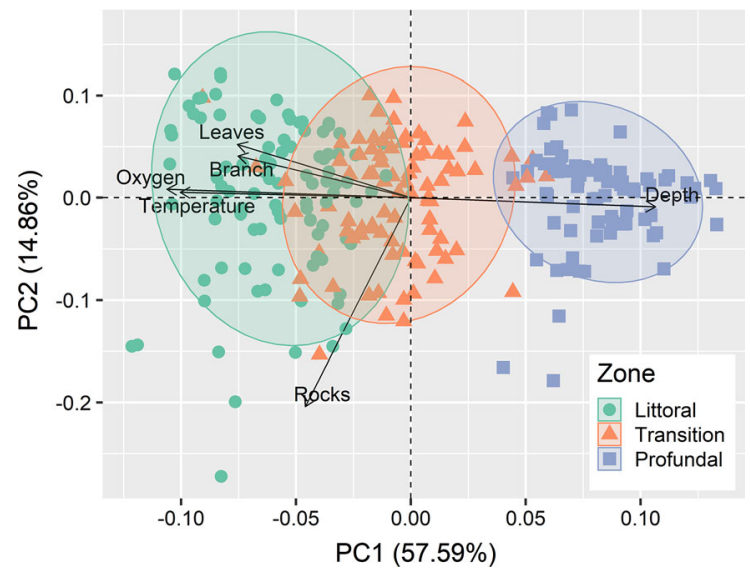

Fig. 3 Ordination diagram from the two first axes of principal component analysis (PCA) on environmental variables in the three zones of the steep slope margins of the Lajes Reservoir, Brazil

zone was associated with intermediate values of the environmental variables in PC1. The second PCA axis (14.8\% of the explained variation) was negatively associated with rocky substrate and reflected intrazonal variation in the littoral and transition zones (Fig. 3; Online Resource 3).

Fish assemblages

A total of 442 specimens comprising in 5 orders, 6 families and 12 species were recorded (Figs. 4 and 5; Online Resource 4). Most individuals were Cichliformes $(\%$ total number, $N \%=75.7)$, followed by Siluriformes $(N \%=17.8)$ and Gymnotiformes $(N \%=3.8)$. The most abundant species were the cichlids (Cichla spp. $N \%=36.6)$, Crenicichla lacustris (Castelnau 1855) $(N \%=16.74)$ and Coptodon rendalli (Boulenger 1897) $(N \%=15.15)$, followed by the catfishes Loricariichthys castaneus (Castelnau 1855) $(N \%=9.72)$ and Pimelodella lateristriga (Lichtenstein 1823) $(N \%=5.2$; Online Resource 4).

Differences in the fish assemblage structure were detected among the vertical zones (PERMANOVA, $F=25.5 ; P<0.001)$ and periods $(P=4.7 ; P<0.01$, Table 2). Paired comparisons indicated significant differences in fish assemblages between the littoral $\times$ transition $(P=28.0 ; \quad P<0.001)$ and littoral $\times$ profundal $(F=31.1 ; P<0.001)$ zones, but not between the profundal $\times$ transition zones $(P=1.52 ; P=0.63$; Table 2$)$. All twelve recorded species were observed in the littoral zone, and five species had distribution restricted to this zone (Fig. 5; Online Resource 4). The non-native cichlids Cichla spp. and $C$. rendalli were the main indicators of the littoral zone according to the MPA $(P<0.01$, Online Resource 5). In the transition zone, seven species were recorded, but no species had occurrence restricted to this zone. Only $L$. castaneus was an indicator of two zones, the profundal and transition zones $(P<0.01)$. In the profundal zone, only four species were recorded, and the small catfish $P$. lateristriga was an indicator species of this zone $(P<0.01)$. Regarding the diurnal changes, the non-native tilapias $(C$. rendalli and Oreochromis niloticus (Linnaeus 1758)) were indicators of the day period, whereas Gymnotus carapo Linnaeus 1758, Metynnis maculatus (Kner 1858) and $P$. lateristriga were indicators of the night period (MPA; $P<0.05$, Online Resource 5).

The littoral zone showed greater fish abundance (N) compared to the other vertical zones $(P<0.001$; Online Resource 6), but no difference was detected for the abundance between the day and night. On the other hand, the species richness (S) was higher in the littoral during the night $(t=11.5 ; P<0.001)$, followed by the transition $(t=8.7 ; P<0.001)$ and profundal zones $(t=2.6 ; P<0.01)$. A comparison of extrapolated species diversity based on Hill numbers $(q=0)$ shows that species richness was estimated to be the highest in the littoral, followed by transition and profundal zones, respectively (Fig. 6).

\section{Discussion}

Underwater drones in reservoirs: biases, challenges and opportunities

Although being valuable tools for monitoring fish in reservoirs, ROVs have methodological biases and limitations. Before using ROVs, researchers must first consider the potential specific effects of the equipment, such as different light intensities and artificial noise, speed, size and depth of vehicle operation (Sward et al., 2019; Monk et al., 2020). In the Lajes Reservoir, it was observed that the fish react differently to the presence of the small ROV, with some specimens ignoring and others being apparently attracted by the equipment. These responses, however, seemed to be punctual and individual, with no clear 


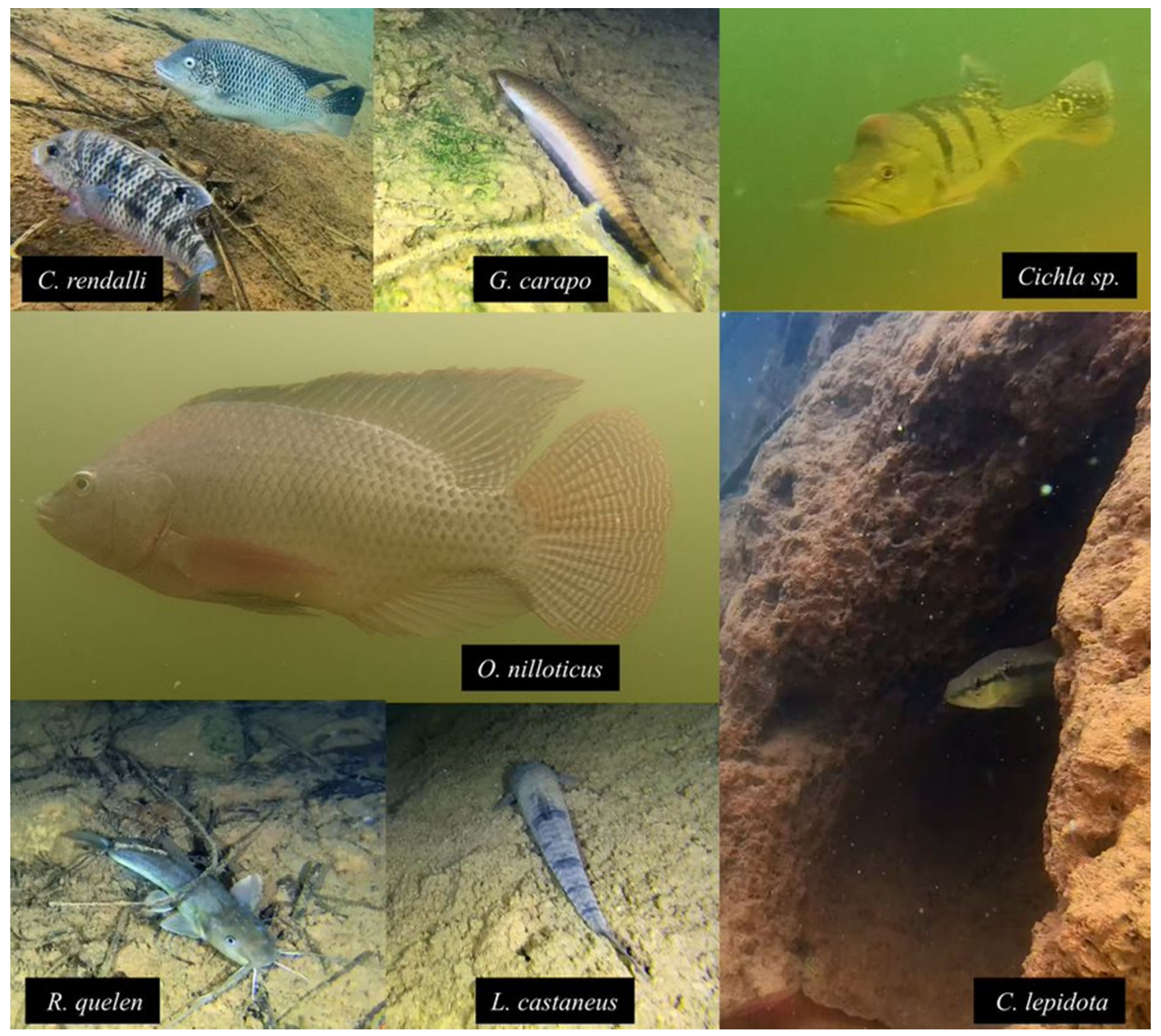

Fig. 4 Photographic records of different species of fish produced by the underwater drones in the Lajes Reservoir, Rio de Janeiro State, Brazil

patterns for a given species or period of the day. Artificial light, for example, can induce different attraction/repulsion responses between highly active/mobile and less active/sedentary species (Ryer et al., 2009). The intensity of reaction to the ROV can further be influenced by a variety of factors, including the species, trophic position and body size (Sward et al., 2019). The use of smaller and less noisy ROVs, as in the current study (weight $4.4 \mathrm{~kg}$ ), has the potential to reduce disturbances previously observed with larger ROV in marine environments.

The structure of the fish assemblages observed with ROV was substantially different from those previously observed with gillnets in the Lajes Reservoir. Catches with gillnets (deployed at the margins during the night period) showed L. castaneus as the most abundant species, followed by the cichlids $C$. rendalli and $C$. lacustris, with relatively intermediate abundance, and $P$. lateristriga as a low frequent/rare species (Araújo \& Santos, 2001; Guedes et al., 2020; Araújo et al., 2021). However, the aforementioned estimates are invariably skewed for different reasons. Loricariichthys castaneus, for example, has an armored body and rough fins, morphological characteristics that facilitate nets entanglement (Hamley, 1975), leading to overestimation of this population. On the other hand, cichlids 
Fig. 5 Boxplots of fish occurrence in different vertical zones $(\mathrm{m})$ along the steep slopes of the Lajes indicate the mean depth of the occurrences. Only species with relative abundance $>3 \%$ of the total number of fish were plotted Reservoir. Red circles

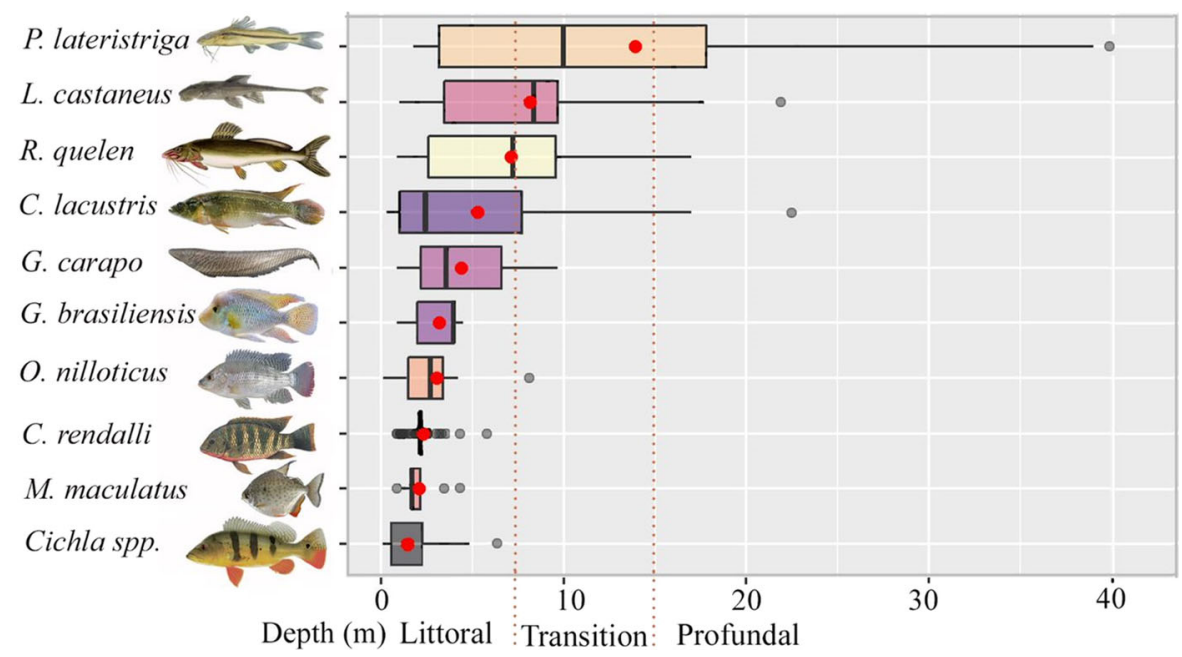

Table 2 Results of PERMANOVA for comparing differences in the fish assemblage structure between the three vertical zones and two periods

$d f$ degree of freedom, $M S$ Mean square; $R^{2}$ coefficient of determination

\begin{tabular}{lllll}
\hline Source & df & MS & Pseudo- F & $R^{2}$ \\
\hline Zone & 2 & 2.33 & $25.54 * * *$ & 0.16 \\
Period & 1 & 0.43 & $4.74 * *$ & 0.015 \\
Zone $\times$ period & 2 & 0.18 & 2.06 & 0.013 \\
Residuals & 254 & 0.09 & & 0.8 \\
Total & 259 & & & \\
Pair wise test for the fixed factors & $t$ & & Period & \\
Zone & $28.0 * * *$ & & Day $\times$ Night & \\
Littoral $\times$ transition & $31.1 * * *$ & & & \\
Littoral $\times$ profundal & 1.52 & & & \\
Transition $\times$ profundal & & & & \\
\hline
\end{tabular}

have advanced visual acuity (Carleton, 2009) and can actively avoid gillnets, with consequent underestimation of their occurrences. As previously shown, $P$. lateristriga occupies deep habitats, in which the gillnets were not effectively able to reach. ROVs, although with their own built-in biases, do not depend on active/passive fish capture and can efficiently sample the deepest reservoir areas. Therefore, the application of ROVs can help to circumvent the selectivity of traditional methods, contributing to more accurate "photographs" of the fish communities, allowing advances in the environmental monitoring of inland waters. However, we recommend future methodological studies comparing both techniques simultaneously to validate this statement.

The hydro-environmental characteristics and prior knowledge of the reservoir ichthyofauna can facilitate the performance of the video transects with ROV. In environments where the ichthyofauna is unknown, the species identification can be potentially erroneous, since characteristics that need to be evaluated at species level are difficult to be observed using videos. In addition, in eutrophic environments (turbid waters) and turbulent flow, the sampling procedure can be difficult due to the impossibility of capturing clear fish images, and to perform transects due to the flowinduced conditions. As reservoirs commonly exhibit well-demarcated environmental flow, transparency and depth gradients, the application may not be appropriate in longitudinal studies (from river to dam). Recently, Lima et al. (2020) synthesized the field challenges and lessons learned of the application of small ROV by water managers in the Netherlands. These included other aspects that also raised concerns, such as the clogging of propellers caused by vegetation, the tangle of the rope with underwater objects and 


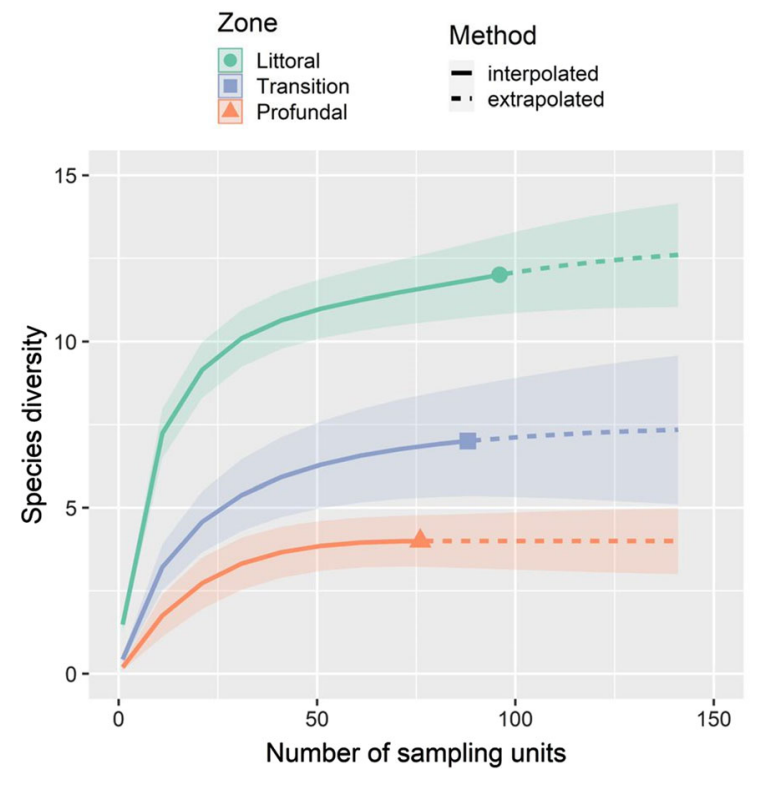

Fig. 6 Rarefaction/extrapolation (R/E) of fish species performed with iNEXT for the studied zones of the Lajes Reservoir, with $95 \%$ confidence intervals

obstacles, and the suspension of sediment and debris induced when vehicles are operated close to the bottom.

The development of compact and less expensive ROVs (from around 3 thousand USD) has made this technology increasingly accessible for environmental monitoring. Traditional sampling programs in reservoirs (e.g. hydroacoustic, boat, multiparameter probe, gillnets) involve a large equipment infrastructure and a high financial cost. In contrast, small ROV coupled to sensors are stored in a handbag and can be conveniently handled from the margins by one or two people. In addition, these vehicles provide in situ observations of fish, their behaviors and habitat associations that cannot be determined with traditional methods (Sward et al., 2019). The ability to be dynamically controlled in "real time" across a variety of depths and habitats, means that the vehicle can inspect vast areas with constant supervision and can be easily focused on areas of interest (Monk et al., 2020). Other accessories, such as suction samplers for benthic fauna, robotic arms, sonar, optical systems to quantify zooplankton and hydrophones, make ROV a flexible tool, with the potential to complement or even replace traditional methods of collecting environmental data (Lima et al., 2020).
Fish assemblages and vertical distribution

A clear change in the fish assemblage structure was found along the steep slopes of the reservoir, with differing environmental characteristics from the littoral to the profundal zones. Non-native species (peacock basses and tilapias) dominated the littoral zone to the detriment of native species. The introduction of these cichlids into the reservoir took place over 60 years ago (Guedes et al., 2021), and the impacts of the introductions have been well documented in different environments (Pelicice \& Agostinho, 2009; Sharpe et al., 2017). In Brazil, species with equilibrium reproductive strategies, such as non-predatory cichlids and small generalist characids, were more successful in occupying the littoral zones of old reservoirs (Agostinho et al., 2016). However, the introduction of predatory cichlids such as the peacock bass has caused reduction in the abundance or even the complete extirpation of small characids (Pelicice \& Agostinho, 2009; Sharpe et al., 2017). Therefore, it is likely that the assemblage dominated by non-native cichlids in the littoral zone is a long-term deleterious effect that resulted in the successful establishment of non-native species and the consequent extirpation of native fish. The profundal zone presented a less structured fish assemblage, with emphasis on the occurrence of $P$. lateristriga, a native species typical of shallow streams that were surprisingly detected exploring the deep reservoir areas (at a depth of $38 \mathrm{~m}$ ). This result shows a wide range of occupation by certain species on the steep slopes of the Lajes reservoir and the absence of completely vacant habitats.

The greatest fish abundance and richness was observed in the littoral reservoir zone, which is characterized by higher oxygen levels and water temperature, and more structured and complex physical habitats, corroborating the main hypothesis of this study. Similar patterns of diversity were observed in the littoral zone of different reservoirs (e.g. Brosse et al., 2007; Gido et al., 2009; Říha et al., 2015; Agostinho et al., 2016; Baumgartner et al., 2018). The presence of submerged trees or branches play a structuring effect in the littoral zone, maintaining and contributing to increase the abundance of species, not only in newly built reservoirs, but also in older reservoirs. (Gois et al., 2012). Furthermore, the higher temperatures and availability of dissolved oxygen in 
the upper layers are critical to the physiology, energy, behavior and growth of fish, and may limit distribution of certain species to the upper layers especially during the period of thermochemical stratification (Pollock et al., 2007; Winton et al., 2019; McMeans et al., 2020). As a result, the reservoir littoral zone is more exploited by fish for breeding, feeding and shelter, thus sustaining great fish abundance and richness.

In the Lajes Reservoir, we observed greater fish richness occurring consistently during the night in the three vertical zones. This may indicate potential horizontal diel migrations, with some species occupying the pelagic/bathypelagic zones during the day and migrating to the steep slopes of the reservoir at night. Although we have no sufficient information to support this hypothesis, similar patterns of daily horizontal movements have been already observed in other reservoirs with different patterns between adults and juveniles (see Čech et al., 2005; Říha et al., 2015; Muška et al., 2018). The reasons for the nocturnal migration of fish to the littoral zones are still unknown. However, the main reason seems to be resting, bioenergetic efficiency, feeding opportunities and predator avoidance (Mehner, 2012; Muška et al., 2013). These factors eventually promote changes in species richness during the diurnal cycle.

\section{Conclusion}

We provided one of the first insights on the application of small ROVs to monitor fish in reservoirs. We found a vertical gradient in environmental characteristics with differing fish assemblage structures along the steep slopes of the reservoir. We showed that greater abundance and richness of fish were observed in the littoral zone, associated with the greater environmental heterogeneity. We also discussed biases, challenges and opportunities of the application of ROV in freshwater systems. The Lajes Reservoir seemed to be an adequate case study due to the predominance of lentic conditions, high water transparency (up to $6 \mathrm{~m}$-Secchi's Disc), and extensive prior knowledge of the ichthyofauna. In general, the scarcity of studies applying ROV's in inland waters still hinder the establishment of robust techniques, protocols and comparisons. It is exactly this gap that makes this technique promising new debates and discoveries in freshwater environment. Underwater drones can be a valuable environmental tool for the simultaneous collection of abiotic and biotic data, especially in deep reservoirs, with variable and complex habitats, resulting in advances in the environmental monitoring.

Acknowledgements We thank Débora Ferreira, Diego Alves and Wagner Uehara for helping in the fieldwork. Paolla Linhares and Ron Fisher helped in the English revision. This research was partially funded by $\mathrm{CNPq}$-Conselho Nacional de Desenvolvimento Científico e Tecnológico (Grant \#304813/ 2015-0) and (130234/2021-4). FAPERJ-Rio de Janeiro State Agency for Research Development also gave a grant to the second author (Proc. E-26/ 203.039/2017).

Funding LIGHT ENERGIA S. A. provided infrastructure and financial (No. 4600004989) support through a monitoring program of the icthyofauna of the Light Reservoir.

\section{Declarations}

Conflict of interest The authors declare that they have no conflict of interest.

Ethical approval This study was authorized by the Ethics Council of Animal Use (CEUA / ICBS / UFRRJ), through Permission 12,179 (03/2017), and the Brazilian Environmental Agency (SISBIO/IBAMA/ICMBio- Permit No. 10,707).

Data availability The data that support the findings of this study are available from the corresponding author upon reasonable request.

Code availability Not applicable.

\section{References}

Agostinho, A. A., L. E. Miranda, L. M. Bini, L. C. Gomes, S. M. Thomaz \& H. I. Suzuki. 1999. Patterns of colonization in neotropical reservoirs and prognoses on aging. In: Tundisi, J. G. \& M. Straskraba (eds), Theoretical reservoir ecology and its applications. Backhuys Publishers, São Carlos.

Agostinho, A. A., L. C. Gomes \& F. M. Pelicice. 2007. Ecology and Management of Fishery Resources in Reservoirs in Brazil. EDUEM, Maringá. (in portuguese)

Agostinho, A. A., F. M. Pelicice \& L. C. Gomes, 2008. Dams and the fish fauna of the Neotropical region: impacts and management related to diversity and fisheries. Brazilian Journal of Biology 68: 1119-1132.

Agostinho, A. A., L. C. Gomes, N. C. L. Santos, J. C. G. Ortega \& F. M. Pelicice, 2016. Fish assemblages in Neotropical reservoirs: colonization patterns, impacts and management. Fisheries Research 173: 26-36.

Alin, S., A. Cohen, R. Bills, M. Gashagaza, E. Michel, L. Tiercelin ... \& G. Ntakimazi, 1999. Effects of Landscape 
Disturbance on Animal Communities in Lake Tanganyika, East Africa. Conservation Biology 13: 1017-1033.

Araújo, F. G. \& L. N. Santos, 2001. Distribution of fish assemblages in the Lajes Reservoir, Rio de Janeiro. Brazilian Journal of Biology 61: 563-576.

Araújo, F. G., M. C. C. Azevedo, G. H. S. Guedes \& W. Uehara, 2021. Assessment of changes in the ichthyofauna in a tropical reservoir in south-eastern Brazil: consequences of global warming? Ecology of Freshwater Fish Early View. https://doi.org/10.1111/eff.12607.

Baumgartner, M. T., G. Baumgartner \& L. C. Gomes, 2018. Spatial and temporal variations in fish assemblage: testing the zonation concept in small reservoirs. Brazilian Journal of Biology 78: 487-500.

Blabolil, P., L. R. Harper, S. Říčanová, G. Sellers, C. Di Muri, ... \& B. Hänfling. 2021. Environmental DNA metabarcoding uncovers environmental correlates of fish communities in spatially heterogeneous freshwater habitats. Ecological Indicators 126: 107698.

Borcard, D., F. Gillet \& P. Legendre, 2011. Numerical Ecology with R, Springer, New York:

Branco, C. W. C., B. Kozlowsky-Suzuki, I. F. Sousa-Filho, A. W. S. Guarino \& R. J. Rocha, 2009. Impact of climate on the vertical water column structure of Lajes Reservoir (Brazil): a tropical reservoir case. Lakes \& Reservoirs: Research \& Management 14: 175-191.

Brazilian Committee of Dams, 2011. The History of Dams in Brazil, Centuries XIX, XX and XXI: Fifty Years of the Brazilian Committee of Dams, CBB, Rio de Janeiro: ((In Portuguese)).

Brosse, S., G. D. Grossman \& S. Lek, 2007. Fish assemblage patterns in the littoral zone of a European reservoir. Freshwater Biology 52: 448-458.

Busch, S. \& T. Mehner, 2009. Hydroacoustic estimates of fish population depths and densities at increasingly longer time scales. International Review of Hydrobiology 94: 91-102.

Cáceres, M. \& P. Legendre, 2009. Associations between species and groups of sites: indices and statistical inference. Ecology 90: 3566-3574.

Carleton, K., 2009. Cichlid fish visual systems: mechanisms of spectral tuning. Integrative Zoology 4: 75-86.

Čech, M., M. Kratochvíl, J. Kubečka, V. Draštík \& J. Matěna, 2005. Diel vertical migrations of bathypelagic perch fry. Journal of Fish Biology 66: 685-702.

Clarke, K. R., P. J. Somerfield \& M. G. Chapman, 2006. On resemblance measures for ecological studies, including taxonomic dissimilarities and a zero-adjusted Bray-Curtis coefficient for denuded assemblages. Journal of Experimental Marine Biology and Ecology 330: 55-80.

Dias, R. M., A. G. Oliveira, M. T. Baumgartner, M. A. AnguloValencia \& A. A. Agostinho, 2021. Functional erosion and trait loss in fish assemblages from neotropical reservoirs: the man beyond the environment. Fish and Fisheries 22: 377-390.

Fernando, C. H. \& J. Holčík, 1991. Fish in reservoirs. International Review in Hydrobiology 76: 149-167.

Gido, K. B., J. F. Schaefer \& J. A. Falke, 2009. Convergence of fish communities from the littoral zone of reservoirs. Freshwater Biology 54: 1163-1177.

Gois, K. S., R. R. Antonio, L. C. Gomes \& A. A. Agostinho, 2012. The role of submerged trees in structuring fish assemblages in reservoirs: two case studies in South America. Hydrobiologia 685: 109-119.

Goulon, S., S. Westrelin, C. Samedy, R. Roy, J. Guillard \& C. Argillier, 2018. Complementarity of two high-resolution spatiotemporal methods (hydroacoustics and acoustic telemetry) for assessing fish distribution in a reservoir. Hydroécologie Appliquée 20: 57-84.

Guedes, G. H. S., T. M. Mattos, G. S. Camilo, W. Uehara, D. L. P. Ferreira \& F. G. Araújo, 2020. Artificial flow regime promotes abiotic and biotic gradients: testing the concept of longitudinal zonation in an off-river reservoir. Ecohydrology \& Hydrobiology 20: 256-264.

Guedes, G. H. S., I. D. Gomes, A. A. Nascimento, F. S. Aguiar \& F. G. Araújo, 2021. Equilibrium reproductive strategy of the peacock bass Cichla kelberi facilitates invasion into a Neotropical reservoir. Journal of Fish Biology 98: $743-755$.

Hamley, J. M., 1975. Review of gillnet selectivity. Journal of the Fisheries Board of Canada 32: 1943-1969.

Hsieh, T. C., K. H. Ma \& A. Chao, 2016. iNEXT: an R package for interpolation and extrapolation of species diversity (Hill numbers). Methods in Ecology and Evolution 7: 1451-1456.

Kay, M. \& J. Wobbrock. 2020. ARTool: Aligned Rank Transform for Nonparametric Factorial ANOVAs. doi:https:// doi.org/10.5281/zenodo.594511. R package version 0.10.8. https://github.com/mjskay/ARTool

Klippel, G., R. L. Macêdo \& C. W. C. Branco, 2020. Comparison of different trophic state indices applied to tropical reservoirs. Lakes \& Reservoirs: Research and Management 25: 214-229.

Kubečka, J., E. Hohausová, J. Matěna, J. Peterka, U. S. Amarasinghe, S. A. Bonar, ..., I. J. Winfield, 2009. The true picture of a lake or reservoir fish stock: a review of needs and progress. Fisheries Research 96: 1-5.

Lewis, V. M., 2009. Ecological zonation in lakes. In Likens, G. (ed), Encyclopedia of Inland Waters. Elsevier, Oxford.

Lima, R. L. P., F. C. Boogaard \& R. E. de Graaf-van Dinther, 2020. Innovative water quality and ecology monitoring using underwater unmanned vehicles: field applications, challenges and feedback from water managers. Water 12: 1196.

Lucas, M. C. \& E. Baras, 2000. Methods for studying spatial behaviour of freshwater fishes in the natural environment. Fish and Fisheries 1: 283-316.

Matthews, W. J., 1998. Patterns in freshwater fish ecology, Chapman and Hall, New York:

McLean, D. L., M. J. G. Parsons, A. R. Gates, M. C. Benfield, T. Bond, D. J. Booth, ..., D. B. O. Jones, 2020. Enhancing the scientific value of industry Remotely Operated Vehicles (ROVs) in our oceans. Frontiers in Marine Science 7: 1-20.

McMeans, B. C., K. S. McCann, M. M. Guzzo, T. J. Bartley, C. Bieg, P. J. Blanchfield, ... \& B. J. Shuter. 2020. Winter in water: differential responses and the maintenance of biodiversity. Ecology Letters 23: 922-938.

Mehner, T., 2012. Diel vertical migration of freshwater fishes proximate triggers, ultimate causes and research perspectives. Freshwater Biology 57: 1342-1359.

Monk, J., N. Barrett, T. Bond, A. Fowler, D. McLean, J. Partridge, ... \& J. Williams. 2020. Field manual for imagerybased surveys using remotely operated vehicles (ROVs). 
In: Przeslawski, R., Foster, S. (eds.), Field Manuals for Marine Sampling to Monitor Australian Waters. National Environmental Science Programme (NESP). https://rovfield-manual.github.io/

Murrie, A., B. Rosenthal, C. R. Saab, G. Durward \& P. B. MacInnes, 2014. Theory and standards. In Christ, R. D. \& R. L. Wernli (eds), The ROV Manual: A User Guide for Remotely Operated Vehicles. Butterworth, Heinemann.

Muška, M., M. Tušer, J. Frouzová, T. Mrkvička, D. Ricard, J. Sed'a, ..., J. Kubečka, 2018. Real-time distribution of pelagic fish: combining hydroacoustics, GIS and spatial modelling at a fine spatial scale. Scientific Reports 8: 5381.

Muška, M., M. Tušer, J. Frouzová, V. Draštík, M. Čech, T. Jůza, ..., J. Kubečka, 2013. To migrate, or not to migrate: partial diel horizontal migration of fish in a temperate freshwater reservoir. Hydrobiologia 707: 17-28.

Oksanen, J., F. G. Blanchet, M. Friendly, R. Kindt, P. Legendre, D. McGlinn, R. Peter ... \& H. Wagner, 2019. Vegan: Community Ecology Package. R package version 2.5-6. https://CRAN.R-project.org/package=vegan

Oliveira, A. G., L. C. Gomes, J. D. Latini \& A. A. Agostinho, 2014. Implications of using a variety of fishing strategies and sampling techniques across different biotopes to determine fish species composition and diversity. Natureza \& Conservação 12: 112-117.

Oliveira, E. F. \& E. Goulart, 2008. Distribuição espacial de peixes em ambientes lênticos: interação de fatores. Acta Scientiarum: Biological Sciences 22: 445-453.

Pelicice, F. M. \& A. A. Agostinho, 2009. Fish fauna destruction after the introduction of a non-native predator (Cichla kelberi) in a Neotropical reservoir. Biological Invasions 11: 1789-1801.

Pollock, M. S., L. M. J. Clarke \& M. G. Dubé, 2007. The effects of hypoxia on fishes: From ecological relevance to physiological effects. Environmental Reviews 15: 1-14.

Pollom, R. A. \& G. A. Rose, 2016. A global review of the spatial, taxonomic, and temporal scope of freshwater fisheries hydroacoustics research. Environmental Reviews 24: 333-347.

Prchalová, M., J. Kubečka, M. Vašek, J. Peterka, J. Sed'a, T. Jůza, M. Říha, O. Jarolím, M. Tušer, M. Kratochvíl, M. ČEch, V. Draštík, J. Frouzová \& E. Hohausová, 2008. Distribution patterns of fishes in a canyon-shaped reservoir. Journal of Fish Biology 73: 54-78.
R Core Team. 2020. R: A language and environment for statistical computing. R Foundation for Statistical Computing, Vienna, Austria. https://www.R-project.org/

Říha, M., D. Ricard, M. Vašek, M. Prchalová, T. Mrkvička, T. Jůza, ..., J. Kubečka, 2015. Patterns in diel habitat use of fish covering the littoral and pelagic zones in a reservoir. Hydrobiologia 747: 111-131.

Ryer, C. H., A. W. Stoner, P. J. Iseri \& M. L. Spencer, 2009. Effects of simulated underwater vehicle lighting on fish behavior. Marine Ecology Progress Series 391: 97-106.

Santos, A. B. I., R. J. Albieri, T. M. Mattos \& F. G. Araújo, 2014. Peixes do Reservatório de Lajes, Wall Print, Rio de Janeiro:

Sharpe, D. M. T., L. F. De León, R. González \& M. E. Torchin, 2017. Tropical fish community does not recover 45 years after predator introduction. Ecology 98: 412-424.

Soares, M. C. S., M. M. Marinho, V. L. M. Huszar, C. W. C. Branco \& S. M. F. Azevedo, 2008. The effects of water retention time and watershed features on the limnology of two tropical reservoirs in Brazil. Lakes \& Reservoirs: Research and Management 13: 257-269.

Straškraba, M. \& J. G. Tundisi. 2013. Water Quality Management of Dams. Oficina de Textos, São Paulo. (in portuguese).

Strayer, D. L. \& S. E. G. Findlay, 2010. Ecology of freshwater shore zones. Aquatic Sciences 72: 127-163.

Sward, D., J. Monk \& N. Barrett, 2019. A systematic review of remotely operated vehicle surveys for visually assessing fish assemblages. Frontiers in Marine Science 6: 134.

Tušer, M., J. Frouzová, H. Balk, M. Muška, T. Mrkvička \& J. Kubečka, 2014. Evaluation of potential bias in observing fish with a DIDSON acoustic camera. Fisheries Research 155: 114-121.

Wetzel, R. G., 2001. Limnology: Lake and River Ecosystems, Academic Press, San Diego:

Winton, R. S., E. Calamita \& B. Wehrli, 2019. Reviews and syntheses: Dams, water quality and tropical reservoir stratification. Biogeosciences 16: 1657-1671.

Publisher's Note Springer Nature remains neutral with regard to jurisdictional claims in published maps and institutional affiliations. 